Научная статья

УДК 159.9 .01

DOI: $10.18101 / 2307-3330-2021-2-40-45$

\title{
СОВРЕМЕННОЕ СОСТОЯНИЕ ПРОБЛЕМЫ ДИФФЕРЕНЦИАЛЬНОЙ ДИАГНОСТИКИ В ПРАКТИКЕ РАБОТЫ СПЕЦИАЛЬНОГО ПСИХОЛОГА
}

\author{
(C) Вялых Ольга Анатольевна \\ кандидат психологических наук, доцент, \\ Российский государственный педагогический университет имени А. И. Герцена \\ Россия, 191186, г. Санкт-Петербург, Набережная реки Мойки, 48 \\ vyalihoa@herzen.spb.ru
}

\begin{abstract}
Аннотация. В статье раскрывается актуальность исследования современных проблем дифференциальной психолого-педагогической диагностики детей с ограниченными возможностями здоровья, рассматриваются основные требования методологии современной психодиагностики и основные требования, предъявляемые современной наукой к практической деятельности педагога-психолога, осуществляющего дифференциальную диагностику детей с ограниченными возможностями здоровья, с целью определения наиболее адекватного их возможностям образовательного маршрута. Проводится анализ наиболее существенных, по мнению автора, проблем реализации дифференциальной диагностики, осуществляемой в психолого-медико-педагогических консультациях, вследствие несовершенства организации этого важного для дальнейшей судьбы детей с ограниченными возможностями здоровья реализации их реабилитационного потенциала развития в условиях специального и инклюзивного обучения, а также показывает основные пути их решения.

Ключевые слова: дифференциальная диагностика, дизонтогенез, психологопедагогическое сопровождение детей с ограниченными возможностями здоровья, подходы и критерии дифференциальной диагностики нарушений развития у детей, структура дефекта, первичные и вторичные факторы в структуре дефекта, психологический диагноз.
\end{abstract}

\section{Для цитирования}

Вялых О. А. Современное состояние проблемы дифференциальной диагностики в практике работы специального психолога // Вестник Бурятского государственного университета. Образование. Личность. Общество. 2021. № 2. С. 40-45.

Дифференциальная диагностика состояний психической сферы детей является одним из важнейших направлений деятельности в практике специального психолога. Известно, что она основывается на установлении качественного своеобразия состояния основных сфер психики ребенка: интеллектуальной, эмоционально-волевой и личностной. Это открывает возможности определения уровня актуального и зоны ближайшего развития, наметить коррекционные и компенсаторные приемы работы с каждым ребенком. Решение этих задач подчинено целевой установке успешного сопровождения детей с ограниченными возможностями развития. На основании данных, полученных в результате дифференциальной диагностики, могут быть сформулированы психологический диагноз и прогноз развития, что открывает перспективу определения образовательного маршрута, который будет способствовать эффективному развитию. Многообра- 
O. A. Вялых. Современное состояние проблемы дифференциальной диагностики в практике работы специального психолога

зие вариантов дизонтогенеза выдвигает особые требования к процедуре психологического исследования. Эти требования зачастую не отражены в готовом виде в существующих пособиях, а выявляются в реальной практике диагностической работы психолога. Задача создания готового алгоритма, позволяющего безошибочно учитывать все эти явления, затруднена. Между тем значение определения варианта дизонтогенеза и в соответствии с ним образовательного маршрута трудно переоценить. Диагностические ошибки недопустимы, потому что цена их может быть слишком высока. Неправильная оценка потенциальных возможностей может негативно сказаться на всей дальнейшей судьбе ребенка.

Возможность достичь более высокого качества психолого-педагогической диагностики во многом определяется пониманием психологических механизмов, лежащих в основе психического развития. На основании имеющихся профессиональных знаний психолог должен выработать обобщенную теоретическую позицию, суть которой заключается в понимании того, каким законам подчиняется развитие нормального ребенка, что изменяется при отклонениях и каким образом эти изменения проявляются в процессе его диагностического обследования.

Методология психодиагностики опирается на ряд принципов, среди которых важнейшими являются комплексный поход, принцип системного изучения ребенка, динамического изучения, качественного анализа полученных в результате психологического исследования данных.

Комплексный подход предполагает требование всестороннего исследования ребенка и особенностей его развития, охватывающего не только интеллектуальную деятельность, но и эмоции, поведение, уровень владения различными видами деятельности, речи, состояние нервной системы, слуха, зрения, двигательных функций, историю развития и соматическое состояние.

Принцип системного изучения предусматривает наряду с выявлением особенностей отдельных психических функций изучение связи между ними, а также установление иерархии и степени выраженности этих связей. Это то, что Л. С. Выготский определял как взаимосвязанную систему первичных и вторичных психологических симптомов, лежащих в общей структуре психопатологического явления. Для осуществления такого анализа необходима не только четкая постановка задач исследования психического развития, но и система научно обоснованных диагностических методик, отвечающих основным современным требованиям, без применения которых затруднительно получить адекватный материал для обоснованного решения диагностических задач.

Принцип динамического подхода к диагностике психического развития базируется на понимании законов, управляющих онтогенезом высших психических функций, последовательности формирования умственных и практических действий и деятельности в целом. Основанием для разработки нормативов психического развития могут являться работы Л. А. Венгера, Л. С. Выготского, П. Я. Гальперина, С. А. Домишкевича, А. Н. Леонтьева, А. Р. Лурия, М. С. Певзнер, С. Я. Рубинштейна, Д. Б. Эльконина и др. Существенным в понимании динамики развития детей с ограниченными возможностями здоровья и/или развития является положение Л. С. Выготского о существовании специфических особенностей, обусловленных структурой дефекта, знание которых и позволяет избегать диагностических ошибок, а также концепция о зонах актуального и бли- 
жайшего развития, обеспечивающая понимание потенциальных возможностей ребенка.

Принцип качественного анализа в диагностике нарушений развития реализуется в отечественной специальной психологии в качестве приоритетного. Количественный анализ предшествует качественному, но именно на основе последнего психолог способен выявить особенности и недостатки проявлений в психической сфере. Вместе с тем еще В. И. Лубовский указывал на тот факт, что теоретически отечественная наука сделала существенный вклад в понимание основных принципов психолого-педагогического процесса, однако дальнейшее научное развитие данных идей и практика их применения обусловили ряд основных групп проблем, в числе которых методологические, методические, терминологические, организационные и кадровые.

Остановимся на некоторых из них, решение которых возможно на организационном уровне уже сегодня, что может способствовать развитию практики применения психолого-педагогической диагностики детей с ограниченными возможностями здоровья.

Из-за повышения требований к качеству дифференциальной диагностики необходимо создание новых методологических подходов, способствующих выработке современных, более эффективных критериев, позволяющих разграничить сходные состояния, а также более эффективно определять степень выявленных недостатков и проблем развития у детей в когнитивной, аффективной и личностной сферах. Имеющиеся в современной специальной психологии подходы недостаточно внедрены в практику диагностики нарушений развития у детей и их психолого-педагогического сопровождения.

В положении о создании психолого-медико-педагогических консультаций указано, что решение о конкретной формулировке диагноза должно осуществляться коллегиально по результатам равноправного обсуждения всеми специалистами, включая и специального психолога. Зачастую в реальности диагноз ставится директивно врачом психиатром или психоневрологом без существенного учета мнения других специалистов. В частности, это обусловлено тем, что психолог не может поставить диагноз, так как не может поставить образования. Получается, что формально психолог имеет право на свое профессиональное мнение, но на практике возникают трудности, поскольку традиционно в формулировании диагноза приоритетная роль всегда принадлежала медикам. Но постановка клинического диагноза не означает автоматического понимания психологических механизмов, лежащих в основе недостатков психического развития и путей их преодоления. При любой клинической форме нарушений возможны свои варианты развития, обусловленные совокупностью социально-психологических и индивидуально-психологических характеристик. Поэтому психологический диагноз и не должен подменяться клиническим. Решение данного вопроса лежит в плоскости межведомственного урегулирования взаимодействия различных специалистов консультаций.

В настоящее время остро стоит проблема разработки и официального утверждения современной психолого-педагогической типологии трудностей психического развития детей. Существует целый ряд психолого-педагогических и клинико-психолого-педагогических классификаций, но они с трудом, а порой и 
O. A. Вялых. Современное состояние проблемы дифференциальной диагностики в практике работы специального психолога

совершенно не соотносятся с клинической терминологией, представленной, например, в МКБ - 10, либо оказываются неполными и неудобными для использования. Кроме того, используемая в практике работы психолога терминология недостаточно четко определена, в результате на практике часто возникают разночтения в понимании одних и тех же терминов не только специалистами разных профилей, но и специальных психологов, работающих в разных ведомствах или придерживающихся различных подходов. В результате проблема формулирования четкого психологического диагноза на официальном уровне в соответствии с имеющимися психолого-педагогическими и клинико-психологопедагогическими классификациями становится одной из приоритетных, но так и не решенных на официальном уровне. Это создает целый ряд препятствий в работе практического психолога. Несмотря на тот факт, что теоретические исследования в данном направлении ведутся сегодня активно. Мы имеем ряд определенных достижений для решения данной проблемы, изложенных в работах Е. Л. Инденбаум, И. А. Коробейникова, Н. Я. Семаго, М. М. Семаго и др., но на практике до сих пор не существует унифицированного алгоритма действий различных специалистов в диагностическом процессе. Имеются отдельные разработки в данном направлении, в некоторых регионах они имеют практику применения, но решение этой проблемы недопустимо оставлять отдельным учреждениям, имеющим муниципальную принадлежность. Она должна быть решена на федеральном уровне. Невозможно решить задачу унификации образования детей с ограниченными возможностями здоровья во всех регионах нашего государства без унификации психолого-педагогического процесса.

В ситуации углубления дифференциации системы специального образования, а также развития системы интегрированного образования лиц с ограниченными возможностями здоровья обостряется проблема нехватки специальных средств диагностики. Существует целый арсенал вербальных и невербальных, психометрических и клинических (патопсихологических) методов, с помощью которых можно выявить как количественные показатели интеллектуального и личностного развития, так и качественные показатели развития, характерные для того или иного варианта дизонтогенеза. Преобладание клинического подхода в дифференциальной диагностике, не позволяющей осуществлять качественный анализ выявленных нарушений в развитии, ослабление весьма перспективного, но не нашедшего пока применения уровневого подхода и в определении трудностей психического развития приводит к тому, что часто психолог определяет степень выявленных нарушений в соответствии с собственным опытом. В связи с этим одним из перспективных направлений представляется разработка именно таких методик, которые могли бы объединить клинический и психометрический подходы. Однако даже разработка самого совершенного инструмента для дифференциальной диагностики невозможна без профессионального использования его специалистом, способным квалифицировано интерпретировать полученные результаты исследования.

Также существует и другая проблема - это унифицированное оснащение психолого-медико-педагогических консультаций и психологических служб в образовательных учреждениях имеющимися стандартизированными методиками психолого-педагогического исследования. В результате психолог-практик часто 
вынужден использовать негодный инструмент просто по той причине, что годный в конкретном учреждении отсутствует. Вместо запрета психологам исполнять свои профессиональные обязанности психолого-педагогического обследования следует разработать перечень необходимого пакета методик для соответствующих учреждений и служб и требования их применения.

В завершение отметим, что практика применения психологопедагогической диагностики невозможна без подготовки соответствующего специалиста - психолога. На проблему качественной подготовки психологов, как кадровой, указывал еще В. И. Лубовский. В настоящее время приходится констатировать, что уровень подготовки этих специалистов, по крайней мере в области дифференциальной диагностики, не становится более совершенным. Программы обучения специальных психологов часто пересматриваются, преимущественно механистически в соответствии с той или иной идеей, которые не учитывают специфику содержания и организацию подготовки данных кадров.

Современный подход к обучению будущих специалистов, - приоритетность самостоятельной работы - не может полноценно решать проблему усвоения знаний, которые, как и в медицине, передаются от учителя к ученику. Также не предусматривается организация практик в психолого-медико-педагогических консультациях. Это при том, что никто не оспаривает тот факт, что качественный анализ полученных диагностических данных познается исключительно с опытом в практической деятельности. В результате отмечается недостаток качества работы психодиагностической службы. Требует решения и проблема подготовки и повышения квалификации высококвалифицированных специальных психологов в области дифференциальной диагностики, которая сегодня является одной из самых востребованных. Эта задача может быть решена при условии разработки новых образовательных программ, предусматривающих теоретические курсы и возможности ознакомления с процессом дифференциальной психодиагностики на практике под руководством опытных специалистов. Для этого необходимо развивать сотрудничество со специальными образовательными учреждениями, а также центрами психолого-медико-педагогической диагностики.

Все описанные проблемы дифференциальной диагностики при правильном подходе могут быть «точками роста», разработка которых могла бы способствовать развитию практической психологической науки и повышению эффективности ее использования непосредственно на местах, поскольку именно диагностическая работа является первым и самым важным этапом в цепи психологопедагогического сопровождения детей с ограниченными возможностями развития.

Литература

1. Домишкевич С. А. Функционально-уровневый подход в психологопедагогической диагностике. Иркутск, 2002. 41 с. Текст: непосредственный.

2. Дунаева 3. М., Коробейников И. А. Основные задачи и содержание диагностики в условиях работы ПМПК // Воспитание и обучение детей с нарушениями развития. 2007. № 4. С. 60-63. Текст: непосредственный.

3. Коробейников И. А. Диагностика нарушений психического развития у детей в контексте проблем интеграции междисциплинарного знания // Дефектология. 2004. № 1. С. 54-60. Текст: непосредственный. 
O. A. Вялых. Современное состояние проблемы дифференциальной диагностики в практике работы специального психолога

4. Коробейников И. А., Инденбаум Е. Л. Проблемы диагностики, коррекции и прогноза при организации сопровождения детей с легким психическим недоразвитием // Дефектология. 2009. № 5. С. 22-28. Текст: непосредственный.

5. Лубовский В. И. Психологические проблемы диагностики аномального развития. Москва, 1989. 102 с. Текст: непосредственный.

6. Семаго Н. Я., Семаго М. М. Проблемные дети: основы диагностической и коррекционной работы психолога. Москва, 2003. 207 с. Текст: непосредственный.

Статья поступила в редакциию 05.06.2021; одобрена после рецензирования 05.07.2021; принята к публикации 29.11.2021.

\section{CURRENT STATUS OF THE PROBLEM OF DIFFERENTIAL DIAGNOSTICS IN PRACTICE OF THE SPECIAL PSYCHOLOGIST}

Olga A. Vyalykh

Cand. Sci. (Psychology), A/Prof.,

Herzen Russian State Pedagogical University

48 Naberezhnaya reki Moyki, Saint-Peterburg 191186, Russia

vyalihoa@herzen.spb.ru

Abstract. The article discusses the relevance of studying current problems of differential psychological and pedagogical diagnostics of children with disabilities, considers the basic requirements of the methods of modern psychodiagnosis, and the basic requirements of modern science and practice to the activity of the educational psychologist, whose task is differential diagnostics of children with disabilities in order to determine the individual educational route. We have analyzed the most significant problems of differential diagnostics carried out in psychological, medical and educational institutions, associated with imperfect organization of this process. Differential diagnostics is an important stage in the development of the individual educational route for personal development and rehabilitation of children with disabilities in the conditions of remedial and inclusive education.

Keywords: differential diagnostics, dysontogenesis, psychological and pedagogical assistance for children with disabilities, approaches and criteria for differential diagnostics of developmental disorders in children, structure of disabilities, primary and secondary factors in structure of disabilities, psychological diagnostics.

\section{For citation}

Vyalykh O. A. Current Status of the Problem of Differential Diagnostics in Practice of the Special Psychologist. Education. Person. Society. 2021; 2: 40-45 (In Russ.).

The article was submitted 05.06.2021; approved after reviewing 05.07.2021; accepted for publication 29.11.2021. 